\title{
«Aconchego do Lar»: Discutindo o Serviço de Acolhimento Familiar
}

\author{
Laís Fernandes Jacobina, Mg. \\ Universidade Federal do Rio Grande do Norte, Brasil ${ }^{\star}$ \\ llana Lemos de Paiva, Ph.D. \\ Universidade Federal do Rio Grande do Norte, Brasil**
}

laisjacobina@hotmail.com

\section{Resumo (analítico)}

O Serviço de Acolhimento Familiar (SAF) se encontra inserido num processo de reformulação da política de proteção dos direitos do público infantojuvenil. Assim, discute-se a implantação do SAF em um município do Nordeste brasileiro, sob a perspectiva dos profissionais do SAF, famílias (acolhedora e de origem), criança acolhida, Conselho Tutelar, Promotor de Justiça e Juiz. A partir de entrevistas semiestruturadas, realizou-se a análise das concepções sobre o SAF, como uma alternativa de cuidados à população infantojuvenil. $O$ estudo mostra que o SAF é considerado uma alternativa de atendimento às crianças e adolescentes, sendo ressaltada a atenção individualizada e a afetividade no contexto do acolhimento. Todavia, existem desafios a serem vencidos, como a maior divulgação do $\mathrm{SAF}$, demonstrando, assim, que ele ainda não se consolidou na rede de atendimento.

\section{Palavras-chave}

Políticas públicas, infancia, adolescencia, Estatuto da Criança e do Adolescente, proteção à infância, acolhimento familiar.

Thesauro

Tesauro da BVS-PSI.

\section{Para citar este artículo}

Jacobina, L. F., \& Paiva, I. L. (2020). «Aconchego do Lar»: Discutindo o Serviço de Acolhimento Familiar. Revista Latinoamericana de Ciencias Sociales, Niñez y Juventud, 18(1), 1-23. http://dx.doi.org/ $10.11600 / 1692715 x .18103$

\section{Historial}

Recibido: 15.01.2019

Aceptado: 23.07.2019

Publicado: 25.11.2019

\section{Información artículo}

Este artigo de investigação científica e tecnológica apresenta os resultados da investigação denominada «Aconchego do Lar: Desvelando o Acolhimento Familiar no RN», realizada entre 25 de março de 2016 e 25 de novembro de 2017. Área: Psicologia. Subárea: Temas em Infância e Juventude. 


\title{
"Warmth of Home": Discussing the Foster Care Service
}

\begin{abstract}
(analytical)
The Foster Care Service (FCS) is part of a reformulation of the protection policy for children and adolescents' rights. The implementation of the FCS in a Brazilian north-eastern municipality is discussed based on the perspectives of professionals, families (foster and biological), foster children, members of the Guardianship Council, Justice Promoters and Judges. Using semi-structured interviews, an analysis of the concepts of FCS was carried out as a care alternative for children and youth populations. The study reveals that FCS is regarded as a care alternative for children and young people, emphasizing individualized assistance and affective relationships in foster care. However, there are challenges that need to be overcome, such as an increase in the coverage of FCS, demonstrating as it has not yet been consolidated in service networks.
\end{abstract}

Keywords

Public policies, childhood, adolescence, Child and Adolescent Statute, child protection, foster care.

\section{«Acogida del hogar»: discutiendo el Servicio de Acogimiento Familiar}

\section{Resumen (analítico)}

El Servicio de Acogimiento Familiar (SAF) se encuentra inserto en un proceso de reformulación de la política de protección de los derechos del público infantojuvenil. En este artículo se estudia la implantación del SAF en un municipio del nordeste brasileño, bajo la perspectiva de los profesionales del SAF, familias (acogedora y de origen), niño acogido, Consejo Tutelar, promotor de justicia y juez. A partir de entrevistas semiestructuradas, se realizó el análisis de las concepciones sobre el SAF, como una alternativa de cuidados a la población infantojuvenil. El estudio muestra que el SAF es considerado una alternativa de atención a los niños y adolescentes, siendo resaltada la atención individualizada y la afectividad en el contexto del acogimiento. Sin embargo, existen desafíos a ser superados, como la mayor divulgación del SAF, demostrando así que todavía no se ha consolidado en la red de atención.

\section{Palabras clave}

Políticas públicas, infancia, adolescencia, Estatuto del Niño y del Adolescente, protección de la infancia, acogimiento familiar.

\section{Información autoras}

[*] Mestre em Psicologia pelo Programa de Pós-Graduação, da Universidade Federal do Rio Grande do Norte (UFRN). Especialista em Avaliação Psicológica pelo Centro Universitário do Rio Grande do Norte (UniRN). Brasil.

iD 0000-0003-1483-0665. Correio eletrônico: laisjacobina@hotmail.com

[**] Professora adjunta do Departamento de Psicologia da Universidade Federal do Rio Grande do Norte (UFRN) do Programa de Pós-graduação em Psicologia da UFRN. Doutora pelo programa integrado de pósgraduação em Psicologia Social da UFRN/UFPB, com período de estágio na Universidad Autónoma de Madrid. iD 0000-0002-3331-2890. Índice H5: 6. Correio eletrônico: ilanapaiva@hotmail.com 


\section{Introdução}

Como modalidade formal de atendimento, acredita-se que o SAF se apresenta como uma proposta ainda inovadora, rompendo significativamente com a cultura da institucionalização, pois a criança ou adolescente passam a fazer parte de uma nova família temporariamente.

$\mathrm{Na}$ América Latina, o acolhimento familiar tem se difundido, o que indica que as políticas de atendimento têm buscado atender ao melhor interesse da população infantojuvenil. Esse processo tem ocorrido com celeridade distinta em cada país e ainda se considera necessário ampliar os investimentos das entidades governamentais e não-governamentais nessa área (Ballester, 2010; Fernández-Daza, 2018; Zavala-Rubilar, 2015).

No Brasil, a história da infância e da adolescência foi marcada por muitas práticas institucionalizantes, que contribuíram para o surgimento de uma cultura de institucionalização que ainda perdura (Rossetti-Ferreira et al., 2012).

Com a promulgação do Estatuto da Criança e do Adolescente (ECA) e, posteriormente, a publicação das Orientações Técnicas para os Serviços de Acolhimento para Crianças e Adolescentes, ocorreram avanços quanto ao direito à convivência familiar e comunitária e à medida protetiva de acolhimento. Todavia, ainda se percebe um descompasso entre a lei e a realidade de crianças/adolescentes acolhidos (Barros, 2015) pois, embora a legislação aponte a criança/adolescente como pessoa dotada de direitos, a concretização dos mesmos está relacionada à configuração social na qual ela se encontra inserida (Lozano-Vicente, 2016).

Assim, mesmo com as mudanças legislativas, a quantidade de crianças/adolescentes acolhidos tem aumentado (Penso \& Moraes, 2016), apesar de se utilizar o princípio do superior interesse desse público como norteador das decisões judiciais (López-Contreras, 2015).

Em relação ao acolhimento familiar, evidencia-se que a maioria dos estudos realizados foram conduzidos em países anglo-saxões e na Espanha (Chaves, 2018), tornando-se 
relevante a produção de conhecimento em países latino-americanos. Apesar das singularidades do contexto investigado, entende-se que esse estudo pode contribuir para as discussões sobre a implementação de SAFs no Brasil e em outros países que vivenciem contextos sociais semelhantes.

Logo, este artigo discute a implementação de um Serviço de Acolhimento Familiar (SAF) de uma cidade com aproximadamente 42652 habitantes, dos quais 3690 vivem em situação de extrema pobreza, dentre eles 871 são crianças de até 9 anos de idade. Participaram da pesquisa nove atores envolvidos no processo de implantação do SAF no município (psicólogo e assistente social, coordenador dos serviços socioassistenciais do município, família acolhedora, família de origem, criança acolhida, representante do Conselho Tutelar, Promotor de Justiça e Juiz de Direito da comarca). Foram utilizadas entrevistas semiestruturadas, realizadas individualmente, seguindo um roteiro preestabelecido. A perspectiva de análise que norteou essa pesquisa fundamenta-se no método dialético crítico, que busca compreender o real como totalidade histórica, entendendo-se que ele só é apreendido parcialmente, considerando as conexões e categorias existentes na realidade (Paiva, 2008).

\section{O Acolhimento Familiar}

O SAF integra a Política Nacional de Assistência Social (Pnas) e é destinado ao atendimento de crianças e adolescentes que estão afastados da família por medida protetiva judicial. Eles passam a residir temporariamente com uma família acolhedora, previamente selecionada e capacitada por uma equipe técnica, para cuidar deles até que a autoridade judiciária emita uma sentença quanto ao seu retorno à família de origem, caso superada a situação violadora de direito, ou colocação em uma família substituta, por meio da adoção (Conselho Nacional dos Direitos da Criança e do Adolescente [Conanda] \& Conselho Nacional da Assistência Social [CNAS], 2009).

No SAF, a criança ou adolescente permanecem em um cenário em que equipe técnica e família acolhedora trabalham em conjunto, buscando ofertar um atendimento individualizado, em contexto familiar e comunitário, possuindo caráter temporário e excepcional (Conselho Nacional do Ministério Público [CNMP], 2013). Logo, o SAF surge como uma possibilidade de evitar a institucionalização mantendo, sempre que possível, o contato das crianças/adolescentes acolhidos com as famílias de origem e extensa.

De acordo com Costa e Rossetti-Ferreira (2009), o ECA e as normativas para os serviços de acolhimento familiar brasileiros, que valorizam a convivência familiar e comu- 
nitária, estão fundamentados em teorias da Psicologia, que reconhecem a família como contexto primordial de desenvolvimento, apontando a importância dos vínculos afetivos com as figuras parentais para o desenvolvimento da criança, além dos efeitos negativos do processo de institucionalização.

Bowlby (1988) acreditava que uma instituição não oferecia um ambiente emocional seguro para bebês e crianças, especialmente as menores, sendo, os cuidados grupais, uma alternativa insatisfatória por não assegurar a qualidade e a continuidade desse cuidado, e não proporcionar à criança a participação ativa na rotina diária do grupo, importante para o seu desenvolvimento social e intelectual.

Apesar das discussões já existentes acerca do tema, apenas no ano de 2009 o ECA foi alterado, ressaltando a preferência do acolhimento familiar em relação ao institucional, de acordo com o artigo $4^{\underline{o}} \S 1^{\circ}$, que afirma que a inclusão da criança ou adolescente em programas de acolhimento familiar terá preferência a seu acolhimento institucional (Brasil, 1990). Diante disso, observa-se perspectiva de mudança de paradigma no âmbito do acolhimento, que aponta um processo de reordenamento na esfera jurídica, política e prática.

Todavia, apesar das mudanças legislativas, dados obtidos em levantamento realizado sobre os serviços de acolhimento entre os anos de 2012 e 2013, revelam que o número de SAFs ainda é reduzido no Brasil, correspondendo a 3.35\% do total de serviços de acolhimento no país, os quais estão distribuídos em catorze estados, que estão predominantemente situados nas regiões Sul e Sudeste (CNMP, 2013).

Avanci et al. (2013), no Levantamento Nacional das Crianças e Adolescentes em Serviços de Acolhimento, identificaram a existência de 144 SAFs no Brasil, havendo 791 famílias acolhedoras cadastradas. Constatou-se que pouco mais de $60 \%$ deles se concentrava na região Sul, 27.1\% na região Sudeste e o restante nas demais regiões (Centro-Oeste, Nordeste e Norte).

Valente (2013) ressalta que o acolhimento familiar promove o estabelecimento de relações interpessoais mais afetuosas, melhor comunicação e consequente desenvolvimento da autoestima e autonomia das crianças e adolescentes acolhidos. Pelissa et al. (2017) também destacaram que estudos indicam que, independente do padrão de relacionamento existente na família de origem, ao ser inserida em outro ambiente familiar, mais ameno e onde seus direitos são assegurados, a criança ou adolescente pode se reestruturar e ressignificar sua experiência, vinculando-se a figuras que oferecerão cuidado e proteção.

No Levantamento Nacional das Crianças e Adolescentes em Serviço de Acolhimento, as famílias acolhedoras relataram que sua função é oferecer acolhida, proteção e cui- 
dado à criança ou adolescente por um período de tempo, acompanhando seu crescimento e desenvolvimento de forma construtiva, assegurando sua convivência familiar, escolar e comunitária (Avanci et al., 2013).

Um estudo realizado no Brasil apontou que mães acolhedoras revelaram ser inevitável nutrir sentimento de amor pelos acolhidos. Esse sentimento perpassa o cuidado dispensado à criança/adolescente, que contribui para o desenvolvimento do acolhido, gerando satisfação na família que observa seus progressos (Mariano et al., 2014). Além disso, percebeu-se que mães acolhedoras apresentaram zelo e afeto em relação ao acolhido, estimulando sua autonomia e propagando regras e limites (Luz et al., 2016).

Também se verificou que as relações, baseadas na reciprocidade, cumplicidade e amor, vão se edificando a partir do momento em que a criança/adolescente consegue estabelecer um vínculo de confiança com a família acolhedora, distanciando-se de suas vivências relativas à violência e à negligência, através do carinho e dedicação que lhes são dirigidos (Kuabara et al., 2016).

De acordo com Mariano et al. (2014), as mães acolhedoras revelaram a necessidade de apoio psicológico para refletirem sobre suas ações e sentimentos, e melhor se adaptarem às mudanças advindas da experiência do acolhimento, pois vivenciavam a satisfação de cuidar da criança/adolescente, apegando-se a ele e, depois, sofriam com o seu desligamento. Portanto, lidar com a provisoriedade desses vínculos, é um desafio que pressupõe uma atenção redobrada da equipe técnica, para que as pessoas envolvidas, crianças e famílias, recebam o apoio necessário para enfrentarem o processo de desligamento, ressignificando suas experiências e tendo o seu luto respeitado.

Mariano et al. (2014) observaram que as famílias acolhedoras preferiam o encaminhamento da criança/adolescente para adoção em detrimento do retorno às famílias de origem. Também se evidenciou que, com o despreparo das famílias acolhedoras para o processo de desligamento, havia o receio da criança/adolescente retornar à situação de vulnerabilidade e a ideia de que a família adotiva teria maior capacidade, condições psicológicas e financeiras para constituir uma família. Todavia, a realização de encontros com as famílias acolhedoras mostrou-se uma interessante estratégia para promover o amadurecimento delas (Selmo \& Oliveira, 2013).

Destaca-se a existência de uma interface entre as ações do SAF e a efetivação do processo de adoção. A família acolhedora deve atuar de forma colaborativa no processo de transição da criança/adolescente para a família substituta, sendo essa uma estratégia importante para minimizar os efeitos oriundos dessas mudanças (Valente, 2013). 
Também cabe atentar para as oportunidades fornecidas à família de origem, pois busca-se a reintegração familiar, sempre que possível. Destaca-se que as formas de cuidados ofertados pelos genitores das camadas mais populares à sua prole, historicamente foram reguladas pelo Estado, através de suas instituições (Ierullo, 2015). Então, é importante que a equipe estimule o papel ativo e a autonomia das famílias, acreditando que podem superar suas dificuldades e cuidar de seus integrantes. Nesse sentido, o contato da família de origem com a criança/adolescente acolhido é imprescindível, devendo ser assegurado e estimulado, pois favorece a formação de laços de confiança e aproxima a família de origem dos profissionais do SAF (Valente, 2013)

Ressalta-se que a violação de direitos no seio familiar, não implica necessariamente na ausência de vínculos afetivos entre a criança/adolescente e seus familiares. Assim, a sua retirada desse núcleo é vivenciada de forma subjetiva (Pelissa et al., 2017). Logo, o cuidado fornecido à família de origem é um aspecto relevante, pois esse núcleo familiar faz parte de sua história. É possível contribuir para o bem-estar da criança/adolescente quando se investe em sua família de origem, sendo oportunizado o retorno seguro ao seu lar e à sua comunidade.

Nesse contexto, a equipe técnica do SAF, a família acolhedora, o Conselho Tutelar e o Sistema de Justiça (Poder Judiciário, Defensoria Pública e Ministério Público) possuem funções específicas, mas atuam de forma integrada visando uma melhor qualidade no atendimento à criança e ao adolescente inseridos no SAF (Conanda \& CNAS, 2009). Deve-se realizar o acompanhamento à criança/adolescente, à família acolhedora e de origem, o que envolve outros atores da rede de atendimento, que atuam de modo colaborativo, para traçar um trabalho de continuidade no atendimento à criança e sua família.

Vale salientar que o acolhimento familiar tem crescido no cenário latino-americano, mas apesar das leis e políticas públicas vigentes, a efetiva aplicação de tal alternativa ainda necessita ser assegurada (Fernández-Daza, 2018).

Diante das particularidades dessa modalidade de acolhimento, bem como da sua relevância social e acadêmica, a presente investigação buscou, a partir da fala dos atores entrevistados, discutir o funcionamento do SAF como uma alternativa de cuidados à população infantojuvenil local, analisando suas potencialidades e dificuldades de implementação. 


\section{Aspectos metodológicos}

\section{Participantes}

A escolha dos participantes realizou-se através de amostra intencional (não probalística), feita a partir da experiência do pesquisador no campo empírico, pautada nos conhecimentos teóricos que relacionam objeto de estudo e corpus a ser estudado (Pires, 2008). Dessa forma, foram incluídos na pesquisa a equipe técnica (composta por psicólogo e assistente social), coordenador dos serviços socioassistenciais do município, um Conselheiro Tutelar, o Promotor de Justiça, o Juiz da comarca, uma família acolhedora e uma de origem, uma criança acolhida, indicadas pelo SAF, totalizando nove pessoas entrevistadas.

Estes profissionais foram convidados e incluídos na pesquisa por integrarem a rede de proteção local e participarem do processo de acolhimento. Quanto à criança e sua família de origem, foram contemplados por serem o público-alvo do SAF. Cumpre ressaltar que se buscou ouvir uma das crianças acolhidas, pois apesar de se afirmar a criança/adolescente como sujeitos de direitos, raramente eles são escutados quanto ao modo com que compreendem sua história de vida e as alternativas que propõem para a resolução de seus problemas (Moreira, 2014). Até o período de finalização desta pesquisa, foram aplicadas 04 (quatro) medidas protetivas de acolhimento em família acolhedora pela autoridade judiciária local, tendo ocorrido o acolhimento de 06 (seis) crianças. A criança selecionada para o estudo foi indicada pela equipe do SAF e foi a única a qual a pesquisa teve acesso.

Todos concordaram em participar da pesquisa, assinando termo de consentimento. Cumpre ressaltar que o projeto desta pesquisa foi aprovado pelo Comitê de Ética local.

\section{Procedimentos e instrumentos}

Foram realizadas entrevistas semiestruturadas com base em roteiros pré-estabelecidos. Por meio das entrevistas, buscou-se apreender o discurso dos atores envolvidos na execução do SAF acerca desta modalidade de atendimento, obtendo informações sobre o papel que desempenham no processo de acolhimento familiar, como ocorreu a implantação do SAF no município e em que medida esse serviço tem se constituído uma possibilidade de cuidados à população infantojuvenil do município. Estas questões emergem em um momento de transição de um modelo assistencial predominantemente institucionalizante para modelos de proteção diferenciados, como o SAF. 
Para uma melhor apreensão dos dados, os áudios das entrevistas foram gravados, para que fossem integralmente transcritos. Em seguida, recorreu-se ao recurso da análise de conteúdo temática para organização e análise dos dados (Gomes, 2007; Cavalcante et al., 2014).

Nesse sentido, foi realizada a leitura das transcrições de forma exaustiva e aprofundada, buscando compreender o conteúdo que emergia, a incidência e a qualidade de cada informação. Na sequência, explorou-se e organizou-se o corpus, com o objetivo de construir os eixos temáticos da pesquisa.

Objetivou-se abarcar a perspectiva dos diferentes atores envolvidos no processo de acolhimento, considerando-se que os mesmos podem apresentar perspectivas distintas acerca deste serviço, pois possuem níveis e tipos de envolvimento diferentes durante o processo de acolhimento. Desse modo, buscou-se analisar criticamente as narrativas produzidas pelos participantes, observando de que modo elas se complementam, se contradizem, além de apreender o seu movimento interno.

Desse modo, foi possível depreender três eixos de análise, a partir dos quais os dados foram organizados e determinados os conceitos teóricos que orientaram a discussão em cada bloco, quais sejam: I -Concepções sobre o SAF; II - O SAF como alternativa de cuidados às crianças e adolescentes e III -O SAF sob a perspectiva dos «acolhidos». Na análise do corpus buscou-se uma relação com o referencial teórico que embasa esse estudo.

A exposição dos dados foi realizada num formato que busca dar voz aos entrevistados, relacionando suas falas e destacando os apontamentos teóricos que possam estar associados aos conteúdos manifestos.

\section{Resultados e discussão}

\section{Eixo 1: concepções sobre o SAF}

Os entrevistados disseram ter conhecido o SAF quando começou a ser implantado e divulgado no município. Apenas o Promotor de Justiça e Juiz haviam mantido contato anterior com a proposta de atendimento, mas no plano teórico. Nesse sentido, observouse que ainda existe considerável desconhecimento sobre o SAF evidenciando-se assim a ausência da disseminação de informações suficientes para gerar clareza quanto a sua finalidade e características (Valente, 2012). 
Quanto às ideias que estão sendo construídas acerca do SAF, observou-se que estiveram relacionadas às peculiaridades desta modalidade de acolhimento, especialmente no que concerne à atenção individualizada, sendo traçado um paralelo com o atendimento fornecido por uma instituição, o qual foi considerado menos benéfico para crianças/adolescentes.

Além disso, foi pontuado que a inserção de uma criança/adolescente no SAF é uma oportunidade de se trabalhar a família de origem, favorecer o desenvolvimento dos acolhidos, o amadurecimento pessoal das famílias acolhedoras, mostrando-se, também, uma alternativa que dispende menos recursos públicos. Os entrevistados também relataram suas concepções e preocupações acerca dos vínculos afetivos construídos nesse contexto, como ilustrado nas falas a seguir.

A assistente social pontuou: «É um serviço maravilhoso, em relação às instituições e os danos que causam para a criança e o adolescente».

A coordenadora dos serviços socioassistenciais do município apontou a questão da atenção individualizada:

Quando eu visito a criança em abrigos como o do município, eu vejo que não existe um aconchego de família, é como se... as crianças estão lá, correndo... aí hora do almoço, senta todo mundo na mesa, não existe um cuidado maior [...] pelo que me repassam, [na família acolhedora] existe um cuidado, existe um aconchego, existe uma preocupação... isso é o que diferencia do abrigo.

O promotor de justiça ressaltou a importância dos serviços alternativos:

O SAF faz parte de uma série de serviços alternativos que existem [...] e poderia se começar a olhar situações como essas porque é um serviço muito mais barato do que você manter um abrigo, e que para a criança é menos traumático do que colocar a criança, ou até mesmo o adolescente, numa instituição.

Por meio de sua fala, é possível refletir que ainda há uma predominância das práticas institucionalizantes e que, também realiza uma comparação entre o impacto provocado pela inserção de uma criança ou adolescente em uma família acolhedora, àquele ocasionado pela institucionalização.

O Conselheiro Tutelar relatou suas impressões ao tomar conhecimento da proposta do SAF: 
Tive uma impressão muito boa, porque a gente vê as dificuldades da instituição daqui, então ampliou mais a nossa visão. Porque lá, assim, é muito limitado, muito imprensado.

Assim, observa-se que entende a existência do SAF como uma ampliação necessária à rede de atendimento à criança e ao adolescente. Destaca-se que ambas as modalidades de acolhimento podem coexistir no município, pois as crianças/adolescentes acolhidos possuem necessidades distintas.

Ao expor seu ponto de vista diante da proposta do SAF, a família acolhedora demonstrou associar o cuidado oferecido à criança, com questões afetivas:

O primeiro pensamento foi que tinha que abraçar a ideia porque iria contribuir significativamente com as crianças, ia ajudar muito mesmo. A ideia também de ser útil né? Você contribuir... o adulto foi feito para proteger né? [...] Com a família acolhedora, a responsabilidade ainda é maior, a criança passa a fazer parte da sua família, do seu dia a dia. A criança chega totalmente sofrida, lesionada, com todos os seus direitos violados, e você vai ter que ali... o que vai sarar todas as feridas é o amor. Acho que famílias acolhedoras são selecionadas assim, até por Deus mesmo, pessoas especiais para fazer parte, porque não é nenhuma questão de remuneração, é questão de você querer fazer alguma coisa. É um serviço muito positivo.

Esse relato demonstra que, em sua concepção, o componente afetivo está relacionado ao sucesso do acolhimento. Também apresenta outro aspecto importante que é a inclusão da criança no dia a dia da família acolhedora, que passa a «fazer parte» dela, envolvendo o sentimento de pertencimento construído nessa convivência.

Nesse sentido, cabe refletir que a afetividade construída na relação entre a família acolhedora e a criança, como se fosse um membro da família, pode se revelar um elemento importante nesse contexto, influenciando positivamente no cuidado que lhe é disponibilizado (Mariano et al., 2014).

Porém, sua fala também apresenta certa romantização acerca das famílias acolhedoras, como sendo pessoas «especiais»e «escolhidas por Deus». Um estudo revelou que grande parte das pessoas interessadas em acolher possuía uma orientação religiosa cristã, o que refletiria na existência de valores como solidariedade e ajuda ao próximo, que as levariam a estabelecer relações comunitárias e familiares buscando assistir aos mais 
necessitados (Bussinger \& Lima, 2014). Outrossim, observou-se que todas as famílias acolhedoras do SAF investigado se declararam cristãs (católicas ou evangélicas).

Por outro lado, a psicóloga pontuou que tem refletido acerca do impacto que o atraso no repasse do auxílio financeiro, causou em uma família acolhedora:

A gente vai ter que ter a consciência de que apesar da gente fazer uma seleção, capacitação, nem todas as famílias vão ser cem por cento. Digamos, que estejam para a gente como 'perfeitas' para receber, acolher uma criança. A gente vai tentar ao máximo se aproximar daquilo que seja um ideal. O que eu pude perceber é que a questão financeira, para algumas, fala muito né?

Assim, reflete que a idealização da família acolhedora deve ser analisada criticamente pela equipe técnica, a qual deve estar atenta para evitar qualquer ameaça de violação de direitos das crianças/adolescentes acolhidas.

Quanto a esse aspecto, a família acolhedora relata seu ponto de vista:

Aqui só tem quatro famílias [acolhedoras], eu acredito que não seja nem tanto pela questão financeira, porque todo mundo tem o seu trabalho e, antes da criança chegar, a gente sobrevivia. Então não é apenas pela questão financeira, até porque é um trabalho exaustivo, não é fácil você ficar integralmente com uma criança.

Cumpre realçar que o Levantamento Nacional realizado por Avanci et al. (2013), revelou que as famílias acolhedoras se sentiram exigidas quanto as suas disponibilidades afetivas e capacidades de proteção, pois é preciso que haja paciência e afeto para lidar com a criança/adolescente acolhido, compreendendo seu comportamento em relação ao seu histórico de vida.

Há que se destacar que, de acordo com Bussinger et al. (2009, apud Bussinger \& Lima, 2014), as famílias das camadas populares foram as maiores interessadas no acolhimento familiar, o que poderia estar associado a suas histórias de vida, fazendo com que buscassem se aproximar da realidade daqueles que necessitam ser acolhidos. Assim, frequentemente necessitam de auxílio financeiro para atender as suas necessidades e dos acolhidos (Baptista \& Zamora, 2016).

O juiz expôs que a formação dos vínculos é algo que the preocupa ao se deparar com a proposta do SAF: 
Naturalmente há um vínculo [...]. No caso de uma família acolhedora, você sabe que aquela criança vem de uma situação de desrespeito dos direitos, aí às vezes a pessoa quer até compensar, trata até melhor do que trataria os próprios filhos. Então eu vejo com preocupação muito grande essa questão da formação do vínculo, e do quanto isso vai ser danoso para a formação da criança na vida, quando ela tiver que cortar essa situação.

Nesse sentido, observa-se a expectativa de que o núcleo familiar acolhedor talvez seja um ambiente demasiadamente positivo, em razão do desejo das pessoas de suprirem as necessidades da criança por se sensibilizarem com sua história de vida. Contudo, reflete-se que esse ambiente também pode ser permeado por divergências, conflitos, desentendimentos, pois tais aspectos fazem parte da dinâmica dos relacionamentos humanos e, consequentemente, do convívio familiar.

O Promotor de Justiça também externou preocupação quanto à formação de vínculos afetivos, nos casos em que o processo judicial demorar a ser concluído, acreditando que esse desligamento poderia gerar um trauma para a criança/adolescente.

A família acolhedora comentou acerca das relações afetivas estabelecidas entre ela e a criança acolhida:

Existe um apego, um pouquinho, não tem como não ter, né? Mas a gente sabe que uma hora ela se vai, tem que ir à melhor condição possível né? Sempre foi trabalhado isso, no treinamento isso foi trabalhado muito, muito mesmo. A gente ia fazer o papel de família por certo tempo, mas que a criança não é nossa, que a gente tinha que dar toda a assistência possível, mas uma hora a criança ia nos deixar.

A fala da família acolhedora demonstra que a questão do surgimento de laços afetivos foi um ponto muito debatido no momento da capacitação, embora reconheça que naturalmente sinta-se vinculada à criança acolhida e que um dia ela sairá de sua residência. Destaca-se que o investimento na capacitação contínua das famílias acolhedoras é de extrema importância, vez que a falha nesse processo fragiliza as relações entre elas e o órgão executor, dificultando a compreensão acerca do importante papel social que desempenham (Avelino \& Barreto, 2015). Além disso, a literatura aponta a importância de investir em campanhas de sensibilização e captação, visando promover uma cultura de acolhimento familiar na sociedade (Viedma et al., 2016).

No tocante à formação de laços afetivos, a psicóloga comenta: 
$\mathrm{Na}$ instituição também existem vínculos, eles também se apegam. Inclusive há uma disputa enorme pelas cuidadoras, se as cuidadoras abraçam primeiro os pequenos, os grandes ficam chateados.

Desse modo, a fala da psicóloga chama a atenção para a vinculação afetiva também no contexto do acolhimento institucional, não sendo essa uma questão exclusiva da modalidade do acolhimento familiar.

Diante da importância dos vínculos afetivos para o desenvolvimento da criança/ adolescente, é indicado que seja propiciada a formação de vínculos entre as crianças/ adolescentes acolhidos e os profissionais das instituições ou famílias acolhedoras (Conanda \& CNAS, 2009).

De acordo com Bowlby (1997), a ausência de oportunidades para estabelecer vínculos afetivos, ou prolongadas e repetidas rupturas de vínculos, podem interferir na condição psíquica do sujeito. Assim, ao passo que se deve promover oportunidades para que as crianças formem vínculos com as figuras de cuidado, deve-se evitar frequentes rompimentos desses laços com as famílias acolhedoras ou profissionais da unidade institucional. Ademais, Bowlby pontua que ao ocorrerem rompimentos nos vínculos afetivos, devem-se proporcionar espaços para que sejam externados os sentimentos advindos $\mathrm{da}$ perda ou ausência da figura de apego, de forma que a criança se sinta respeitada e compreendida, recebendo apoio para enfrentar esta experiência. Logo, observa-se a importância de se trabalhar os vínculos afetivos ao longo desse momento $d a$ vida $d$ a criança ou adolescente, vez que o período de convivência no contexto do acolhimento é temporário, mas não necessariamente curto.

Também foram pontuadas as fragilidades do SAF, às quais estariam relacionadas ao interesse das famílias acolhedoras pelo recurso financeiro, ao horário de funcionamento restrito do SAF, ao pequeno número de famílias acolhedoras cadastradas, bem como a um possível vazamento de informações quanto às crianças/adolescentes acolhidos, conforme relatos ilustrativos:

A psicóloga expôs a situação de uma família acolhedora que se mostrava muito interessada no recebimento do recurso financeiro:

O fator negativo que eu vejo, são essas questões que vão surgindo e as crianças vão se deparando e não compreendendo né? Como essa questão financeira: «Espera aí, eu sou uma mercadoria para ela?» [família acolhedora] 
Diante disso, a coordenadora comunicou que é importante realizar o desligamento daquelas famílias que visam apenas à questão financeira.

Baptista e Zamora (2016) destacaram que, em vários países, as famílias acolhedoras majoritariamente estão situadas nas classes populares e precisam de suporte financeiro para atender às necessidades materiais das crianças e adolescentes acolhidos. Todavia, Girard (2004, apud Baptista \& Zamora, 2016) explica que o desejo de ser uma família acolhedora pode estar relacionado ao fato da família gostar e querer acolher, aliado à necessidade financeira de subsistência, um aspecto concreto que não diminuiria seu comprometimento com o trabalho, sendo um dos estímulos para o acolhimento e, não necessariamente, o principal.

O Juiz pontuou a questão de o funcionamento do serviço não ocorrer em escala de plantão, havendo momentos em que os profissionais não estão disponíveis para o SAF, além de ter se preocupado com a circulação de informações quanto ao paradeiro das crianças, em virtude de uma possível falta de preparo das famílias acolhedoras e do próprio porte do município, sugerindo a realização de uma espécie de intercâmbio de crianças/ adolescentes para famílias acolhedoras de outras cidades.

\section{Eixo 2: o SAF como alternativa de cuidados às crianças e adolescentes}

Os entrevistados, de forma geral, demonstraram abertura à proposta do acolhimento familiar:

É uma casa que acolhe, é um lar, é onde tem mais cuidado. É onde a criança, pelo menos foi a percepção que eu tive, está se sentindo acolhida mesmo, se sentindo protegida, cuidada e até mesmo amada, porque quando cuida né? Existe um amor ali. Então eu notei isso nas crianças. Uma felicidade, um prazer em estar ali, não percebi que estavam tristes, infelizes. Com certeza existem várias dores ali, mas elas me passaram muita tranquilidade. (Psicóloga)

Nesse sentido, destaca-se que o pensamento apresentado pela profissional do SAF se coaduna àquele exposto por outros psicólogos que atuam nesse contexto, que entendiam esse serviço como uma oportunidade de crianças e adolescentes vivenciarem o cuidado individualizado, em um ambiente familiar disposto a acolher, fornecendo afeto e atenção de forma diferente do contexto institucional. Assim, é percebido como uma alterna- 
tiva extremamente saudável para os acolhidos, assegurando seus direitos à proteção, afeto, educação e saúde de qualidade (Luz et al., 2016).

Durante a entrevista, tanto a equipe técnica como a coordenadora, destacaram a possibilidade de uma família acolhedora responsabilizar-se por qualquer perfil de criança e adolescente. Porém, reconhecem que isso depende das características e da disponibilidade das famílias acolhedoras, sendo importante o fornecimento de subsídios que deem condições para assumirem tal função.

O juiz apresentou preocupação quanto ao público adolescente:

O meu sonho é que isso se espalhe pelo Brasil todo, é uma alternativa muito positiva. O grande problema são os adolescentes, porque receber uma criança de dois ou três anos de idade, cinco, todo mundo recebe.

O Conselheiro Tutelar destacou que entende o SAF como uma alternativa de cuidados:

Se a família acolhedora aceitar receber grupo de irmãos, daria certo. Eu vejo mais a família acolhedora para as crianças menores de 12 anos, certo? Porque adolescente é mais complicado, tem rebeldia, não querem obedecer.

A preocupação com relação aos adolescentes, perpassa o senso comum de que a adolescência é uma etapa crítica do desenvolvimento humano, em que os relacionamentos se tornam mais complicados. Na experiência brasileira, alguns serviços relataram possuir dificuldades de conseguir famílias disponíveis ao acolhimento de adolescentes com mais de 14 anos de idade que, geralmente, também resistem ao acolhimento e visam conquistar sua autonomia (Rizzini et al., 2006). Assim, se mitos e preconceitos têm provocado resistências nas famílias acolhedoras (Avanci et al., 2013), acredita-se que a equipe técnica pode buscar reduzi-los trabalhando tal temática nas capacitações promovidas.

\section{Eixo IIII: o SAF sob a perspectiva dos «acolhidos»}

Ao longo da investigação, observou-se que os relatos da família de origem e da criança acolhida apresentavam traços singulares e delicados. Assim, considerou-se importante assegurar um espaço apenas para suas falas.

A genitora, quando questionada acerca da sua opinião no que diz respeito à permanência de suas filhas em uma família acolhedora temporariamente, ficou alguns instan- 
tes em silêncio, e depois respondeu: «Sei lá». A sua postura e fala denotaram a possível inexistência de uma opinião formada, ou até mesmo o desejo de não responder a essa pergunta, por remeter a um aspecto difícil para ela.

Diante disso, vale salientar que frequentemente a atitude de algumas famílias, especialmente das mães, de «deixarem» seus filhos acolhidos, é interpretada como um comportamento negligente, de abandono, de falta de afeto e responsabilidade para com os filhos. Todavia, tal postura pode evidenciar a internalização do sentimento de impotência e incompetência desses familiares, que frequentemente se encontram sem possibilidades de lidar com as condições de sua existência (Mariano et al., 2014).

Em outro momento da entrevista, a genitora mencionou quão delicado é para ela o afastamento de suas filhas: «Está uma coisa muito ruim para mim, né? Muito triste porque sem os filhos a gente não é nada». Logo, consegue demonstrar seus sentimentos quanto a isso. Por meio de sua fala percebeu-se uma desvitalização, enfraquecimento dela diante desta realidade, como frequentemente ocorre em muitas famílias brasileiras, que se deparam com questões provenientes de um contexto de vulnerabilidades sociais para as quais não enxergam possibilidades de superação. Nessa perspectiva, Dias (2009), identificou a existência de sofrimento nas famílias de origem das crianças e adolescentes inseridos no SAF.

Quanto à criança entrevistada, ela relatou que sua estadia na família acolhedora estava sendo «ótima», acrescentando: «Ainda bem que eu estou lá [na família acolhedora]». Depois falou que só desejava retornar para o convívio da família de origem, se fosse para ficar sob os cuidados do genitor, demonstrando fragilidade no vínculo com a figura materna, embora sua irmã desejasse voltar a morar com a mãe.

Ao longo do relato da criança observou-se que ela considera positiva a sua permanência na família acolhedora. Além disso, relatou que gostaria de encontrar uma família como a família acolhedora, dizendo que: «Ela dá carinho a gente, não briga com a gente e não dá pisa na gente». Referiu que às vezes saem juntos para passear na praça de skate ou na casa de uma amiga da família.

Por meio de seu relato, observa-se que a família acolhedora passou a ser uma referência de cuidados para a menina, realçando a existência do respeito e da afetividade nesse convívio, aspecto salutar para a continuidade do seu desenvolvimento e adaptação ao momento vivenciado. Assim, considera-se que a primazia das relações afetivas estru- 
turantes reafirmam a prioridade do acolhimento em contexto familiar (Delgado \& Gersão, 2018).

Outrossim, sua fala também aponta o convívio comunitário ao afirmar que passeiam na praça e visitam conhecidos. Desse modo, verifica-se que é possível promover a continuidade da socialização da criança ou adolescente acolhido (CNMP, 2013). Além disso, Valente (2013) pontua que no contexto comunitário, as crianças e adolescentes inseridos na família acolhedora sofrem menos com a estigmatização do que aqueles acolhidos em instituições.

Sobre as coisas das quais não gosta, a menina falou que não se sente bem nas ocasiões em que a tia acolhedora grita. Ao ser indagada sobre o que motiva a tia acolhedora a gritar, respondeu: «A gente arenga. É porque às vezes minha irmã arenga e eu sou chata com ela, com tia. Eu respondo ela. Quando a gente não arenga ela fica feliz».

Por meio dessa fala, é possível observar que o contexto da família acolhedora, apesar de ser positivo em alguns aspectos, também possui conflitos e divergências. Logo, não se apresenta como um contexto "perfeito», isento das situações cotidianamente vivenciadas no âmbito familiar ou institucional.

\section{Considerações finais}

Ao longo desta investigação, evidenciou-se que os entrevistados consideram o acolhimento familiar como uma interessante alternativa de atendimento às crianças e adolescentes, ressaltando seus aspectos positivos, especialmente a atenção individualizada, a afetividade existente no convívio entre a criança/adolescente e a família acolhedora, bem como a permanência da criança/adolescente em um ambiente familiar, o qual consideraram mais salutar que o institucional. A criança entrevistada, ao destacar que no contexto do acolhimento familiar recebia carinho, e desejava encontrar um lar definitivo em que também pudesse vivenciá-lo, revela que tal aspecto é importante sob a perspectiva de quem é acolhido.

Todavia, observou-se que ainda há uma resistência quanto ao acolhimento de adolescentes e pré-adolescentes, por existirem ideias preconcebidas quanto a esse público.

Além disso, a questão dos vínculos afetivos construídos no contexto da família acolhedora foi um aspecto paradoxal na pesquisa, havendo uma ênfase nesses laços, tanto 
como algo positivo, que favoreceria a adaptação e o bem-estar da criança; como negativo, pois poderia interferir no processo de reinserção familiar ou colocação em família substituta, em virtude de possível dificuldade para o rompimento do vínculo entre família acolhedora e a criança/adolescente.

Nesse sentido, questiona-se se, ao se tentar evitar que uma criança/adolescente estabeleça laços afetivos saudáveis, por medo de que sofra com o rompimento desses vínculos, não se limitaria as suas possibilidades de vida, sua liberdade de conviver e construir sua afetividade da forma como lhe é possivel, especialmente em um momento em que estão privadas de seus vínculos familiares e comunitários? Negar o «aconchego» a quem não pode encontrá-lo em outro lugar, que não aquele em que está vivendo temporariamente (numa família acolhedora ou em uma instituição), seria a melhor forma de «prevenir problemas» futuros ou de lidar com esse aspecto?

Pensar e cuidar desses laços afetivos mostra-se um desafio e uma tarefa essencial, que envolve a responsabilidade daqueles que produzem conhecimento acerca do tema, e dos profissionais que lidam diretamente com as crianças/adolescentes e famílias. Logo, este aspecto demanda uma atenção especial para que essas relações sejam trabalhadas adequadamente.

Nesse sentido, considera-se relevante a realização de novos estudos qualitativos, pois a vinculação afetiva é uma experiência inerente aos relacionamentos humanos, tendo sua importância reconhecida para a saúde mental dos indivíduos, especialmente para crianças e adolescentes que se encontram em importante momento do seu processo de desenvolvimento humano.

Ademais, observou-se que a inserção da modalidade do acolhimento familiar na rede socioassistencial, ainda tem sido vivenciada com reservas por alguns atores, apesar dos acolhimentos realizados até o momento terem sido bem sucedidos, de maneira geral. Como toda prática nova, que exige um saber diferenciado e estratégias de atuação diversificadas, são despertadas incertezas quanto à sua efetividade. Tais questionamentos possivelmente só encontrarão resolução com a continuidade do SAF, quando será possível a esses atores, analisarem com maior propriedade o seu funcionamento.

Um limite a considerar deste estudo é que ele não se propõe a ser representativo de todos os programas de acolhimento familiar, pois os participantes são residentes de um município de pequeno porte. Apesar de trazer importantes reflexões acerca das potencialidades e limites do SAF, ressalta-se que há fatores discutidos aqui que dizem respeito 
às questões culturais e dinâmica da rede local. Por fim, destaca-se que discutir essa temática contribui para aclarar as peculiaridades das políticas públicas que visam o atendimento a crianças e adolescentes em situação de risco, favorecendo assim a adoção de modelos de atendimento que melhor atendam às suas necessidades.

\section{Referências}

Avanci, J. Q., Carvalho, M. J. B., \& Assis, S. G. (2013). Serviços de Acolhimento em família acolhedora. En S. G. de Assis, \& L. O. P. Farias (Orgs.), Levantamento nacional das crianças e adolescentes em serviço de acolhimento (pp. 291-348). Hucitec.

Avelino, D. A. O., \& Barreto, M. L. M. (2015). A família acolhedora e a política pública: um modelo em avaliação. Oikos: Revista Brasileira de Economia Doméstica, 26(1), 143-173.

Ballester, C. A. (2010). La adaptación del menor al proceso de acogimiento familiar: un enfoque ecológico [Tese de Doutorado]. Universitat Jaume I.

Baptista, R., \& Zamora, M. H. (2016). É possivel profissionalizar as famílias acolhedoras no Brasil? Polêm!ca, 16(2), 14-28. https://doi.org/10.12957/polemica.2016.22906

Barros, K. B. T. (2015). O direito à convivência familiar e comunitária: um estudo sobre o programa de famílias acolhedoras na cidade de São Luís nos anos de 2012 e 2013 [Dissertação de Mestrado, Universidade Federal do Maranhão]. Plataforma Sucupira. https://sucupira.capes.gov.br/sucupira/public/consultas/coleta/trabalhoConclusao/ view TrabalhoConclusao.jsf?popup=true\&id_trabalho=2383056

Bowlby, J. (1988). Cuidados Maternos e Saúde Mental. Martins Fontes.

Bowlby, J. (1997). Formação e Rompimento dos Laços Afetivos. Martins Fontes.

Brasil. (1990). Lei no 8.069. (13 de julho). Dispõe sobre o Estatuto da Criança e do Adolescente e dá outras providências. Congresso Nacional.

Bussinger, R. V., \& Lima, N. E. (2014). Análise das motivações de famílias candidatas ao Programa Família Acolhedora de Vitória. Argumentum, 6(2), 218-232. https://oi.org/ 10.18315/argumentum.v6i2.7504

Cavalcante, R. B., Calixto, P., \& Pinheiro, M. M. K. (2014). Análise de conteúdo: considerações gerais, relações com a pergunta de pesquisa, possibilidades e limitações do método. Informação \& Sociedade: Estudos, 24(1), 13-18.

Chaves, S. P. (2018). Constrangimentos e potencialidades associados à medida do acolhimento familiar de crianças e jovens [Dissertação de Mestrado, Instituto Universitário de 
Lisboa]. Repositorio ISCTE. https://repositorio.iscte-iul.pt/bitstream/10o71/17110/1/ master_sara_pedro_chaves.pdf

Conselho Nacional do Ministério Público. (2013). Relatório da infância e juventude-Resolução 71/2011: um olhar mais atento aos serviços de acolhimento de crianças e adolescentes no país.

Conselho Nacional dos Direitos da Criança e do Adolescente, \& Conselho Nacional da Assistência Social. (2009). Orientações técnicas: serviços de acolhimento para crianças e adolescentes.

Costa, N. R. A., \& Rossetti-Ferreira, M. C. (2009). Acolhimento familiar: uma alternativa de proteção para crianças e adolescentes. Psicologia: Reflexão e Crítica, $22(1)$, 111-118. http://dx.doi.org/10.159o/So102-79722009000100015

Delgado, P., \& Gersão, E. (2018). O acolhimento de crianças e jovens no novo quadro legal. Novos discursos, novas práticas? Análise Social, (226), 112-134. http://dx.doi.org/ 10.31447/ASooo32573.2018226.05

Dias, W. A. (2009). Construções possíveis: o convívio em um projeto de acolhimento familiar. [Dissertação de Mestrado, Pontifícia Universidade Católica de São Paulo]. Biblioteca digital PUC-SP. https://sapientia.pucsp.br/bitstream/handle/17970/1/ Walkyria\%2oAcquesta\%2oDias.pdf

Fernández-Daza, M. P. (2018). El acogimiento familiar en Iberoamérica. Saúde e Sociedade, $27(1), 268-289$. http://dx.doi.org/10.1590/s0104-12902018170647

Gomes, R. (2007). Análise e interpretação de dados de pesquisa qualitativa. Vozes.

Ierullo, M. (2015). La crianza de niños, niñas y adolescentes en contextos de pobreza urbana persistente. Revista Latinoamericana de Ciencias Sociales, Niñez y Juventud, 13(2), 671-683. https://doi.org/10.11600/1692715x.1328020615

Kuabara, C. Y. S., Klipan, M. L., \& Abrão, J. L. F. (2016). Família acolhedora: o estabelecimento de relações objetais em situação de acolhimento. Estilos da Clínica, 21(2), 346-365. https://doi.org/10.11606/issn.1981-1624.v21i2p346-365

López-Contreras, R. E. (2015). Interés superior de los niños y niñas: definición y contenido. Revista Latinoamericana de Ciencias Sociales, Niñez y Juventud, 13(1), 51-70. https://doi.org/10.1160o/1692715x.1311210213

Lozano-Vicente, A. (2016). Los derechos del niño: cuestiones sobre su fundamentación. Revista Latinoamericana de Ciencias Sociales, Niñez y Juventud, 14(1), 67-79. http:// dx.doi.org/10.1160o/1692715X.1413290515

Luz, A., Tronco C., \& Gelain, D. (2016). Quem ama acolhe! Mas quem ama devolve? Revista de Psicologia da Criança e do Adolescente, 7(1-2), 417-431. 
Mariano, P. P., Cecilio, H. P. M, Paz, R. C. N. Decesaro, M. N., \& Marcon, S. S. (2014). Cuidan-do de quem não tem família: percepção de mães acolhedoras sobre esta experiência. Psicologia USP, 25(1), 21-32. http://dx.doi.org/10.159o/ S0103-65642014000100003

Moreira, M. I. C. (2014). Os impasses entre acolhimento institucional e o direito à convivência familiar. Psicologia \& Sociedade, 26(n. spe. 2), 28-37. https://doi.org/10.1590/ So102-71822014000600004

Paiva, I. L. (2008). Os novos quixotes da psicologia e prática social no âmbito do terceiro setor [Tese de Doutorado, Universidade Federal do Rio Grande do Norte]. Repositorio Institucional UFRN. https://repositorio.ufrn.br/jspui/handle/123456789/17579

Pelissa, M. D., Silveira, D. M., \& Murara, M. A. (2017). O serviço de acolhimento familiar em São Bento do Sul e o processo de desligamento das crianças: o desafio da desvinculação afetiva. Novos Saberes, 4(1), 32-46.

Penso, M. A., \& Moraes, P. J. F. S. (2016). Reintegração familiar e múltiplos acolhimentos institucionais. Revista Latinoamericana de Ciencias Sociales, Niñez y Juventud, 14(2), 1523-1535. http://dx.doi.org/10.11600/1692715x.14243180815

Pires, A. P. (2008). Amostragem e pesquisa qualitativa: ensaio teórico e metodológico. En J. Poupart, J. P. Deslauriers, L. H. Groulx, A. Lapemère, R. Mayer, \& A. P. Pires, (Org). A pesquisa qualitativa: enfoques epistemológicos e metodológicos (pp. 154-211). Editora Vozes.

Rizzini, I., Rizzini, I., Naiff, L., \& Baptista, R. (2006). Acolhendo Crianças e Adolescentes. Cortez.

Rossetti-Ferreira, M. C., Almeida, I. G., Costa, N. R. A., Guimarães, L. A., Mariano, F. N. Teixeira, S. C. P., \& Serrano, S. A. (2012). Acolhimento de crianças e adolescentes em situações de abandono, violência e rupturas. Psicologia: Reflexão e Crítica, 25(2), 390-399. http://dx.doi.org/10.1590/So102-79722012000200021

Selmo, J. T., \& Oliveira, J. A., de. (2013). Os desafios e possibilidades do trabalho do serviço social no programa famílias acolhedoras no serviço de acolhimento. Seminário Integrado, $7(7), 2-18$.

Valente, J. (2012). Acolhimento familiar: validando e atribuindo sentido às leis protetivas. Serviço Social \& Sociedade, 111, 576-598. http://dx.doi.org/10.1590/ So101-66282012000300010

Valente, J. (2013). Família acolhedora: as relações de cuidado e de proteção no serviço de acolhimento. Paulus. 
Viedma, I., Míguez, M. A., Santaló, C., \& Martín, A. (2016). Modelo de intervención y retos en el acogimiento familiar: la experiencia de la Fundación Márgenes y Vínculos. Apuntes de Psicología, 34(2-3), 281-29o.

Zavala-Rubilar, M. I. (2015). Acogimiento familiar en Chile: análisis de los perfiles familiares y del ajuste de los niños y niñas [Tese Doutorado]. Universidad de Sevilla. 